\title{
ACTIVITIES OF THE INSTITUTE OF WELDING IN GLIWICE IN THE FIELD OF TRAINING THE PERSONNEL FOR WELDING PRODUCTION
}

\author{
J. PILARCZYK \\ Institute of Welding \\ 16/18 Bl. Czeslawa Str., 44-100, Gliwice, Poland. E-mail: is@is.gliwice.pl
}

\begin{abstract}
The Institute of Welding in Gliwice is the largest and very important research center in Poland, which carries out works on research, development and implementation in all the fields and directions of welding production, that is very helpful in the process of education and training the personnel. The research staff members of the Institute, who have been working for decades in many fields of welding production, combine a profound theoretical knowledge with a huge laboratory experience within their specialties, and due to that the valuable results of practical cooperation with industrial enterprises fully meet the requirements specified to the educators of the highest level. 3 Ref., 1 Table.
\end{abstract}

Keywords: welding production, training of personnel, harmonization, European and international systems, training and supervision centers, local education centers

Training activities of the Institute of Welding in Gliwice [1] are carried out in several main areas:

- education and training of welding personal (engineers, technologists and masters of welding as well as welders) in the framework of the harmonized European and international systems;

- maintenance and supervision of the internal system for training welders at the local training centers;

- training of personnel in the field of nondestructive testing methods, covering all of the most important methods and techniques;

- courses on non-destructive testing methods in the field of railway transport;

- different special courses.

Training of welding personnel in the framework of harmonized European and international systems. This training is carried out in a close cooperation with:

- EWF (31 members) (European Federation for Welding, Joining and Cutting, formerly European Welding Federation) [2], founded in 1992 after the establishment of the European Union. The main task of EWF was the development of the Harmonized Education and Training System of personnel for welding production on the highest, medium and professional levels, which would ensure the issue of a single sample of documents, that would be irrevocably recognized in all the Member States without need in testing the knowledge and skills of persons who passed the education;

- IIW (56 members) (International Institute of Welding [3], founded in 1947, and included into the

(C) J. PILARCZYK, 2016 harmonized system of training the welding personnel in 2000, when the decision was taken to establish the IAB (International Authorization Board), comprising two groups: group A on matters of education, training and qualification, and group B on implementation of the systems and its authorization. The international auditors group (Lead and Peer Assessors) was established. In the countries which entered the system, the Authorised National Bodies IIW-ANB and IIWANBCC were established, exactly the same as those operating in EWF.

The authorized national bodies examine and certify the persons, who finished the preparatory courses, carried out by the education authorities ATB (Approved Training Bodies) approved by these organizations.

The harmonized system of education, qualification and certification of personnel responsible for supervision of welding processes is currently based on the IIW recommendations. The basic document IAB 252 of 2007, which determines the principles of system operation, is subjected to systematic revision in the subsequent publications.

At the present time the IIW-ANB status belongs to the institutes and welding organizations in the following countries (in alphabetical order): Australia, Austria, Belgium, Brazil. Bulgaria, Canada, Croatia, Czech Republic, Denmark, Finland, France, Germany, Hungary, India, Indonesia, Iran, Italy, Japan, Nigeria, Norway, China, Poland, Portugal, Republic of Korea, Romania, Russia, Serbia, Singapore, Slovakia, Slovenia, South Africa, Spain, Sweden, Switzerland, Thailand, The Netherlands, Turkey, Ukraine and the United Kingdom. 
The International and European system of harmonized training, qualification and certification of personnel includes the following levels.

The personnel responsible for supervision of welding:

- International/European Welding Engineer;

- International/European Welding Technologist;

- International/European Welding Specialist;

- International/European Welding Practicioner.

The rest of the personnel:

- International/European Welder;

- International/European Welding Inspection Personnel: $\mathrm{C}$ - comprehensive, $\mathrm{S}$ - standard, and $\mathrm{B}$ - basic.

The knowledge and diplomas received in the framework of harmonized training system allow finding a job in the open labor market in all the countries of the world. The availability of comprehensively trained welding personnel with the appropriate documents confirming the special knowledge has a fundamental importance in the countries involved into production of steel structures in a large volume. To these countries Poland also belongs, which currently occupies the second place in Europe (after Germany) in the field of production of steel welded structures. In Poland more than a half of steel rolled products is produced, which are then processed into welded structures and products. In total, Poland produces more than 1 million tons of welded structures, about half of which is exported.

As was mentioned above, in Poland the supervision of system of the international harmonized training in the field of welding is carried out by ANB, which is the Institute of Welding in Gliwice, more exactly the Center for Certification Authority founded by the Institute. The training is conducted in the ATBs, approved by ANB. The first ATB in Poland was the Center for welding training and supervision of the Institute of Welding. The Center has the authority to conduct education at all the levels starting from welding engineers, and finishing with welders.

In the boldest forecasts it was not supposed that, since 1997 the activities in the field of education and training of welding personnel would be demanded in such a large volume and carried out for such a wide range of the concerned persons. Due to a growing number of comers, the Institute invited the Polish higher education institutions to cooperation, where education of welding specialties was carried out. Based on the formal agreements between the directors of these institutions and the director of the Institute the ATB status in the field of training the engineers of welding (IWE/EWE) was received by the following institutions:
- Wroclaw University of Technology, Mechanical Faculty; Institute of machine technologies and automation, Welding department;

- Gdansk University of Technology, Mechanical Faculty, Chair of materials technology for machines and welding production;

- West Pomeranian University of Technology in Szczecin, Faculty of mechanical engineering and mechatronics, Welding department;

- Czestochowa University of Technology, Faculty of mechanical engineering and informatics, Welding department;

- University of Technology and Humanities in Bydgoszcz, Faculty of mechanical engineering;

- Warsaw University of Technology, Faculty of production engineering;

- Cracow University of Technology, Mechanical Faculty, Institute of materials engineering

At the same time, several ATB were established for training welders and mid-level personnel in welding at different education centers throughout the whole country.

In total, the number of international diplomas issued in 1999-2014 amounted to 3558, of which IWE - 2080; IWT - 247; IWP - 197; IWS - 524; IW - 31; IWIP - 479 pcs.

The number of European diplomas issued in 19972014 amounted to 1620, of which EWE - 1120; EWT - 179; EWP - 158; EWS - 72; EW - 91 pcs.

Center for welding training and supervision. The Center for welding training and supervision acting at the Institute of Welding for over 25 years, was created after 1990 first of all to conduct the harmonized European education. However, the beginning of the Center activities was initiated much earlier and coincided with the moment of the Institute foundation, when the State Welding Institute established by the existing government in 1945 received the only but very urgent task of training gas and electric welders, who at that time were very much needed for restoration of Poland, seriously damaged as a result of combat actions during the Second World War.

The European education had to be carried out at the corresponding level. In this regard, the Center was projected and organized on a large scale and using the significant funds at the huge efforts of many staff members of the Institute. The rooms of the Center look attractively, and its rich technical facilities are closely connected with the equipment of the whole Institute. Due to that the Center fully meets all the theoretical and practical requirements specified for the modern welding education at the highest level.

The Center for welding training and supervision is an integral organizational link of the Institute and is directly subordinated to the Director of the 
Institute. It acts on the basis of the general charter, organizational statute of the Institute and the own Charter. The activities of the Center are controlled by the Scientific Council of the Institute. The Institute is included into the lists of non-public institutions of continuing education and to the Register of educational establishments.

The Center for the first time received the authorization and status of the Polish ATB in 1996, and the validity of authorization is systematically prolonged.

The main activity of the Center is continuous education of personnel for welding production. At the Center the special training of welding personnel is organized and conducted at all the levels in accordance with the IIW and EWF programs: I/EWE, I/EWT, I/ EWS, I/EWP and I/EWIP. While conducting the IWE (EWE) courses the Center uses ATB assistance at the Polish higher technical institutions conducting education, which follows from the content of the programs in the parts I, II and III. The final phase of the last part covering the laboratory studies and demonstrations of modern welding equipment is held at the Center and at the territory of the whole Institute.

The other forms of activities of the Centre in the field of education and training of the personnel is the maintenance and control of the Polish system of training of welders at the local training centers throughout the whole country, the courses in the field of non-destructive testing methods and special courses.

Maintenance and control of the Polish system of training welders at the local education centers. The Institute of Welding was involved in training welders during the first several years of its activity. Then, training of welders was mastered by numerous training centers scattered throughout the country. The quality of this training was different, there was no method for helping the weaker centers, neither a unified system of issuing documents and introduction of new principles for training welders in accordance with the requirements worked out by the European standards applied in other countries. In order to help training centers and, at the same time, to ensure the appropriate level of training welders in Poland, the Institute decided to conduct the following works:

- objective supervision of training welders all over Poland (education is conducted in accordance with the national programs);

Documents issued in the period of 2004-2014
- certification of Polish centers for training welders (in Poland there are more than 400 of such centers);

- checking of examiners conducting examinations on the basis of authority granted by the Institute of Welding (in Poland there are about 160 of such of examiners);

- issuing documents to welders on the basis of the examination protocols sent to the Institute;

- welder's qualification examination certificate according to PN-EN 287-1 or PN-EN ISO 9606 in English or German version for graduates of courses in fillet welding or welding of sheet steel and pipes;

- welder's qualification examination certificate in fillet welding or welding of sheet steel and pipes in the welded structures of the $1^{\text {st }}, 2^{\text {nd }}$ and $3^{\text {rd }}$ class according to PN-M-69008, manufactured from sheet steel or pipes;

- welder's certificate.

The number of documents issued in the period from 2004 to 2014 is given in the Table. The system of supervision has proved itself also today. After several decades of improvement nobody claims against the rationality of its implementation.

Courses in non-destructive testing methods. Since 2002, the Center for welding training and supervision provides training of personnel in NDT methods. The courses are conducted at the Institute (at the special laboratories, equipped with the advanced equipment for all the testing methods) and outside it (if the customer expresses such a desire) on the basis of the own programs developed on the basis of international requirements. The examination, attestation and certification of students is conducted by the Centre for Certification of the Institute in accordance with the requirements of standard PNEN ISO 9712:2012 (until 31.12.2012 it was standard PN-EN 473:2008) «Non-destructive testing Aattestation and certification of NDT personnel». The graduates of the courses receive the certificates of competence and the certificates of specialists in NDT.

The courses are conducted in the following NDT methods: visual testing (VT), penetrants testing (capillary) (PT), ultrasonic testing (UT), magnetic particles testing (MT), X-ray testing/radiographic evaluation of welds (RT2 ORS) and radiographic testing/technique of performing X-ray photos/ RT evaluation. Three levels of NDT personnel certification are applied. In case of the $3^{\text {rd }}$ level the course covers the Basic part and the basic method.

\begin{tabular}{|c|c|c|c|c|c|c|c|c|c|c|c|}
\hline Type of document & 2004 & 2005 & 2006 & 2007 & 2008 & 2009 & 2010 & 2011 & 2012 & 2013 & 2014 \\
\hline $\begin{array}{c}\text { Welder's qualification } \\
\text { examination certificate }\end{array}$ & 20,566 & 22,487 & 34,576 & 42,423 & 43,789 & 46,199 & 44,454 & 42,499 & 45,075 & 52,884 & 52,592 \\
\hline Welder's certificate & 8740 & 10,580 & 15,474 & 21,524 & 17,604 & 14,736 & 13,918 & 13,662 & 17,378 & 18,234 & 18,390 \\
\hline
\end{tabular}


The graduates of the courses RT2 ORS may gain admission to carrying out control in the industrial sector for manufacture of welded products (w), products subjected to plastic processing, except for forgings (wp) and pipes of different diameters and wall thickness $(t)$.

Graduates of PT MT, UT and RT courses may gain admission to carrying out testing in the industrial sector on manufacture and the sector on testing before manufacture and in-process testing together with manufacture of welded products (w), castings (c), forgings (f), products subjected to plastic processing except of forgings pieces (wp), and pipes of different diameters and wall thickness $(\mathrm{t})$.

The courses in NDT methods are of great concern at the Polish market, which is evidenced by the statistics on the number of participants of these courses.

A number of persons, who passed training at the courses, in 2004 was 727; 2005 - 708; 2006 - 729; $2007-864 ; 2008-960 ; 2009-849 ; 2010-982$; $2011-916 ; 2012$ - 938;2013 - 927; 2014- 1220 .

Considering the numerous, often very specific requirements in the field of NDT, the Institute of Welding began cooperation with the transport technical inspection (TDT) in Warsaw, the result of which was the development of courses in NDT in the field of railway transport at the industrial sector «Maintenance of railway transport». At the Institute the specialized laboratory was founded equipped with the elements of rail cars, which in practice are subjected to NDT, as well as equipment allowing carrying out the appropriate testing method. The education is carried out according to the methods of UT, PT and MT in accordance with the requirements of standard PNEN ISO 9712:2012 (previously PN-EN 473:2008). Education is completed with examination, conducted by TDT. The certificates of NDT personnel are issued by the certifying body, which is TDT-CERT.

Special courses. A special group of preparatory and educational courses carried out at the Institute of Welding is the special courses, including:

- course of European welder of synthetic materials (course is organized by the EWF program, examination - in accordance with PN-EN 13067 standard);

- course of welder of pipelines of synthetic materials (course is organized by the program IS, examination - in accordance with PN-EN 13067 standard);

- course for the personnel on supervision in the manufacture of pipelines of synthetic materials for water and gas supply (course is organized by the program IS, examination - in accordance with PNEN 13067 standard).

In case of passing the examination with a positive result, the graduates will receive a certificate of competence CEPW.
For joining the modern materials and producing the critical structures the adhesion bonding is increasingly used. The Institute of Welding in cooperation with the Fraunhofer Institute in Bremen organized the courses of adhesion bonding: the European adhesion bonding technician and the European specialist in adhesion bonding (in accordance with the EWF recommendations EWF 515 and EWF 516. The course is completed with passing the written and oral exams and practical exam. After finishing the course the participants receive the European certificate. The course includes joining of metal, glass, elastomers, plastomers and synthetic materials reinforced with fibers.

In addition, at the Institute of Welding the training in the field of macroscopic and microscopic metallographic examinations of structural materials and their welded joints is carried out at three levels:

- basic - preparation of specimens for macroand microscopic metallographic examinations;

- standard - inspection module, i.e. evaluation of quality of welded joints on the basis of the approved evaluation criteria; and

- comprehensive level.

After passing the exam with a positive result, the graduates receive the document for basic standard/ comprehensive level (Record of Achievement) by the EWF, recognized in all the countries of the European Union.

Computer system for servicing the welding personnel. The activity of the Institute of Welding in the field of training and education of welding personnel requires a systematic and very clear documentation of all the actions related to this activity, both directly at the Institute (at the Centre for welding training and supervision and at the Certification Center), and in all the external education centers cooperating with the Institute. Before 2007 the documentation proceeded in the traditional way, i.e. with the participation of staff members of the Institute filling the documents manually. When the amount of incoming documents increased so dramatically that the traditional bureaucratic methods were unable to process them and it was impossible to meet the growing demands to the quality of servicing and the terms of performing the tasks, the Institute took a decision on using the modern information methods and systems.

Planning the development of the modern Institute of Welding, already in 1995 the Informatics Department was established in the organizational structure, which main objective was to create the appropriate information structure to perform three types of tasks: realization of current research and development works carried out by the Institute staff members (internal computer network), providing the development of international cooperation on a wide 
scale (Internet) and the use of modern computer systems in the field of management and activity of the company (ERP - Enterprise Resource Planning, and CRM - Customer Relationship Management).

The revolutionary changes taking place at a rapid pace of the world information technologies has always found its reflection in the Institute. The first computer network was established in 1990 on the basis of already nonexistent standard ArcNet. The administrative and management programs covering finances, personnel and accounting (FK network) were introduced. The network was launched operating in the Novell environment. Over the time at the Institute the new computer devices and the modern, more complex computer programs appeared. The old technology was replaced by a new one of the Ethernet type. In connection with the requirements to security and privacy of data the FK network is autonomous. At the Institute the network equipment as well as servers and their operation system were gradually changed.

At the present time, in accordance with the international trends, at the Institute the solutions are used, the purpose of which is to provide the highest level of security and high availability, i.e. the servers are running in a cluster, they are controlled by the programs for virtualization and the data are accumulated in the redundant disc matrices. At the input of the local computer network, interconnecting about 150 devices with the port for connection to the Ethernet (servers, workstations, specialized research equipment and welding equipment operating in the network of control and monitoring), the network equipment of the highest quality is installed, which performs the Firewall, AntiVirus, Deep Inspection, WebFiltering and AntiSpam functions. All the active network devices are fully controllable, cooperate with the monitoring software and operate in the Ethernet standard $1 \mathrm{Gbit} / \mathrm{s}$. The main framework of the network is produced using the multifiber, multimode lightguide using link aggregation.

In creation of the computer infrastructure at the Institute the Informatics Department staff members are involved. The applied information solutions were implemented without changes (software virtualization and control of the computer network), or subjected to modification in order to meet the specific aspects of the Institute activities (EPR and CRM systems). Such modification occurred in the case of informatization of the system of training the welding personnel.

The experience gained during the several decades allowed creating the computer system in Poland for servicing the welding personnel (KSOP), covering the territory of the whole country. The main objective of KSOP was its versatility and eliminating the need in installing any software on the user's computer (some institutions and systems do not permit the user's interaction to the existing software). In KSOP system the Internet technology was used, due to which the access to the system is provided by the search system at any time of the day and from any place on the Earth.

KSOP, servicing the welding personnel, comprises training, examination and certification:

- of welders at the authorized education centers;

- and supervision of the certificate of NDT personnel;

- and also supervision of the certificate according to the international requirements of IIW/EWF for all the levels realized today (IWE, IWT, IWS, IWP, IWIP, IW, EPW), and after the special EWF courses at the authorized ATB Centers (in the startup process).

The development and introduction of KSOP were facilitated by two information projects that were implemented at the Informatics Department of the Institute:

- "The system of information and communication in the field of education of welding and NDT personnel as the element of competitiveness growth among the enterprises in the field of welding production", the realization of which took place from 2006 to 2008, was co-financed from the European Social Fund within the framework of the Integrated Operational Program of regional development, Action 2.6: «Regional innovation strategies and knowledge transfer», and Priority 2: «Strengthening the human resources development in the regions».

Within the frames of this project the following databases were created: the EU Directives, harmonized standards, guidelines and standards for products in the part concerning education and certification of welding and NDT personnel; institutions and forms of education in the field of training welding and NDT personnel in compliance with the European and international requirements. The system of preparation and delivery of urgent news «Newsletter» was also prepared. At present, in the system more than 400 companies and nearly 800 individual users are registered, and there is also the site in the Internet, the content of which is oriented to support the education and training of welding personnel in the broadest sense of the word. The constantly updated content of databases and the volume of knowledge provided on the website meet the constant relentless interest. In 2007-2015 the site was visited by about 25000 people;

- In the frames of the second project PO1G.02.03.00-00-003/10 "Information welding platform of knowledge and research potential at the simultaneous expanding of the information structure of the Institute of Welding》, the realization of which took place from 2011 to 2013, the server cluster was mounted and launched, the main task of which is to provide the reliability and productivity of the system of providing databases to the academic environment 
created within the frames of the project: research works and technological solutions, technological needs of enterprises, research of potential academic institutions, structural materials, fatigue tests, issues related to environmental engineering in welding, and issues concerning education and training of welding and NDT personnel.

The process of integration of KSOP with the knowledge bases for academic environment resulted in creation of Information Platform of the Institute of Welding (IPS). IPS is subjected to continuous expanding, the next new modules are launched, the best example is the advisory system i-EkoSpawanie developed in 2015, which will be available for users at the beginning of 2016. The system i-EkoSpawanie is designed for welding technologists, employers, employees, departments of labor safety and designers of ventilation systems. This system allows optimizing the welding process in order to reduce the risks associated with evolution of dust and welding fume to minimum. System databases contain characteristics of welding processes and welding consumables from the point of view of the type and amount of evolved harmful substances.

From the very beginning of IPS creation the possibility was suggested to use it also by the users outside the Poland. For this purpose in the system the multi-lingual dictionaries (Polish-English-German and any two additional languages) are used.

Due to launching the on-line access of the education centers to KSOP, the period of time between drawing up the examination protocols and receiving the documents confirming the qualification was significantly reduced (even to one week). Thus, the inconvenience connected with errors, which significantly prolong the period of documents transfer to the interested persons, was largely eliminated. The education centers using KSOP have the opportunity to view all the qualifications, courses and students (however only and exclusively registered at the Center). The system can also help in controlling the qualifications, allows preparation of different types of reports, for example, on welding methods, validity terms, etc. The fact of reducing the costs associated with regular sending of documents by post or by courier service is also essential, which occurs in the case of centers not connected to the system.

KSOP is used by more than 400 centers for training welders, of which 103 - are on-line users. All the courses of NDT personnel end in issuing documents due to the existence of KSOP, which, moreover, allows also conducting the full supervision of certificates. Starting from 2013 the system is used by seven higher educational institutions: in Gdansk, Wroclaw, Szczecin, Czestochowa, Bydgoszcz, Warsaw and
Krakow. In the system 291 users are registered (as to the end of October, 2015), which carry out serving of courses, attestation, certification and supervision of admission action. KSOP is introduced gradually in the next education centers. So far (as to the end of October, 2015) on the KSOP base 380,206 documents were accumulated for the qualifications issued to 204,210 students on the basis of 112,625 examination protocols. Each year the database is enlarged with the several tens of thousands of records.

\section{Conclusions}

Over the past 25 years in Poland a huge step forward was made in the field of training personnel for welding production, satisfying all the requirements for quantity and quality both inside the country as well as in the framework of international cooperation.

Poland (Institute of Welding) cooperates with EWF since 1992; in 1996 the Certification Center of the Institute received the status of ANB-EWF, in 1997 the Institute became a full member of EWF.

Poland (Institute of Welding) cooperates with IIW since 1958 (in the field of training personnel since 1998) and is a full member of IIW; in 1998 the Certification Center of the Institute received the ANB-IIW status.

The Center for welding training and supervision of the Institute of Welding is the first, the largest and the most active ATB in Poland (conducts education on the IWE/EWE, IWT, IWS and IWP programs).

In Poland, except of ATB at the Institute of Welding, seven ATB are functioning at the higher education institutions (conduct education on the IWE/EWE program) and two ATB at the Centers for education (conduct training on the IWS and IWP programs), which received the authorities from the Institute of Welding.

In all the ATB in Poland in the period from 1996 to 2014 more than 5,000 of welding personnel passed the education.

At the several hundred education centers, which are under supervision of the Institute of Welding, tens of thousands of welders were trained, mainly in accordance with national programs (however, the documents received by welders are recognized abroad).

The system of harmonized, European and international training, attestation and certification of personnel on welding supervision, as well as national and international system of training welders are the necessary conditions for realization of international cooperation in the field of manufacture of welded structures and products.

\footnotetext{
1. $w w w$.is.gliwice.pl

2. $w w w$.ewf.be

3. $w w w$.iiwelding.org
} 